\title{
SOLIDARIEDADE E DIREITOS FUNDAMENTAIS NA CONSTITUIÇÃO BRASILEIRA DE 1988
}

\author{
Paulo Sergio Rosso*
}

\begin{abstract}
RESUMO
Discorre sobre o princípio constitucional da solidariedade, inter-relacionando-o aos direitos fundamentais. Tece breve histórico sobre as origens do direito de solidariedade, fixando-as no cristianismo e nos ideais socialistas. Elenca as bases de direito positivado que fazem menção ao princípio da solidariedade, como a atual Constituição brasileira e a Declaração Universal dos Direitos Humanos. Analisa a presença do princípio da solidariedade nas já revogadas Constituições brasileiras. Procura situar o princípio da solidariedade na classificação dos direitos em dimensões (ou gerações) concluindo que o mesmo pode ser catalogado como de terceira ou quarta dimensão, de acordo com os critérios adotados. Prova a relação existente entre o princípio da solidariedade e os direitos fundamentais, citando alguns direitos previstos no ordenamento constitucional, intimamente ligados ao princípio em questão. Demonstra a influência do princípio da solidariedade no direito tributário. Salienta a importância do estudo do princípio para o direito constitucional, já que contribui para humanização do direito. Remata defendendo a importância do princípio como contribuinte para efetivação dos direitos fundamentais e justificador da própria existência desses direitos.
\end{abstract}

Palavras-chave: Solidariedade; Direitos Fundamentais; Dimensões de Direitos; Princípios Constitucionais.

\begin{abstract}
SUMÁRIO: INTRODUÇÃO; 1 ORIGEM DO PRINCÍPIO DA SOLIDARIEDADE; 2 SOLIDARIEDADE E AS DIMENSÕES DE DIREITOS; 3 SOLIDARIEDADE E DIREITOS FUNDAMENTAIS; CONSIDERAÇÕES FINAIS; REFERÊNCIAS.
\end{abstract}

* Procurador do Estado do Paraná, Mestrando em Ciência Jurídica pela UENP/FUNDINOPI, Professor de Sociologia Jurídica e Direito Tributário pela FANORPI. Email: ps_rosso@yahoo.com.br. 
"Tem sentido falar de solidariedade para reafirmá-la ou para definitivamente sepultá-la."

(Cláudio Sacchetto).

\section{INTRODUÇÃO}

Muito comumente encontram-se operadores jurídicos frustrados com a efetividade do direito. Embora a Constituição brasileira de 1988 tenha trazido evidentes inovações à ordem jurídica, incorporando conceitos de democracia, liberdade, solidariedade, participação popular e outros temas hoje considerados de primeira grandeza, a realidade esbarra nas limitações materiais do Estado ou na própria natureza humana daqueles que deveriam zelar pelo cumprimento de tão nobres objetivos.

Sem razão, entretanto, afiguram-se as queixas. O direito é, propriamente, um objetivo a ser alcançado. A lei, apenas, não muda a sociedade, embora sirva como contribuinte para mudanças. E o direito é, e sempre será uma aspiração, um ideal.

Disso recende a beleza do trabalho desempenhado pelo doutrinador jurídico, pelo professor de direito, pelo advogado, pelo juiz, pelo acadêmico: sua missão é aproximar a realidade dos ideais do direito. Angustiar-se pela demora na implantação ou mesmo pelos fracassos é atitude compreensível, mas inútil e equivocada.

Daí decorre a constatação da importância de se possuir uma Constituição ousada em termos democráticos e humanitários: mais do que uma simples norma jurídica, ela é um ideal cultivado por toda a sociedade.

É o caso da milenar aspiração por uma sociedade solidária: o homem sonha com um mundo unificado, com sociedades pacíficas onde reinem a concórdia e a felicidade. Entretanto, sua natureza parece se opor a isso, seu individualismo cego põe em risco não apenas a convivência humana, mas a própria vida no planeta Terra. Cabe 
ao estudioso do direito aprofundar-se nos caminhos teóricos do direito, construindo um eficiente arcabouço jurídico e, especialmente, estudando formas de implantação dessas teorias. Pobre do jurista que se esqueceu de sonhar.

O momento é bastante propício ao estudo da solidariedade porque nossa sociedade hoje corre o risco de perder o conceito de responsabilidade pública ${ }^{1}$, ante a descrença no Estado e o quadro de competitividade e individualismo exacerbado.

Este trabalho pretende, primeiramente, demonstrar a existência do ideal solidarista em nossa Constituição, conceituando-o e demonstrando sua recepção, pelo ordenamento, na forma de princípio constitucional. Em seguida, procura-se realizar a interligação entre o princípio da solidariedade e os direitos fundamentais previstos pela Constituição brasileira.

\section{ORIGEM DO PRINCÍPIO DA SOLIDARIEDADE}

Solidariedade, segundo os dicionários, define-se como "sentimento que leva os homens a ajudarem-se mutuamente"; outro vocábulo, bastante próximo e por vezes utilizado como sinônimo é "fraternidade", definível como "parentesco de irmãos, convivência como de irmãos, amor ao próximo".2

O termo solidariedade tem sua origem associada ao étimo latino solidarium, que vem de solidum, soldum (inteiro, compacto). ${ }^{3}$ Sacchetto ${ }^{4}$ define magistralmente o termo como uma forma de pensar contrária ao egoísmo.

O sentimento de solidariedade é próprio do ser humano, sendo mais forte à

${ }^{1}$ SACCHETTO, C. Solidariedade social e tributação. In: GRECO, M. A.; GODOI, M. S. de. [coord.]. Solidariedade social e tributação. São Paulo: Dialética, 2005. p. 11.

${ }^{2}$ RIOS, D. R. Dicionário global da língua portuguesa. 4. ed. São Paulo: DCL, 2004, p. 667.

${ }^{3}$ NABAIS, J. C. Solidariedade social, cidadania e direito fiscal. In: GRECO, M. A.; GODOI, M. S. de. [coord.]. Solidariedade social e tributação. São Paulo: Dialética, 2005. p. 111.

${ }^{4}$ SACCHETTO, op. cit., p. 15. 


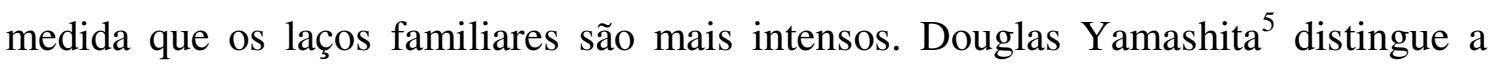
solidariedade de grupos sociais homogêneos e solidariedade genérica. A primeira seria a solidariedade existente entre pessoas pertencentes a um grupo específico (familiar, por exemplo), enquanto a segunda espécie diria respeito à sociedade como um todo.

Pode-se constatar que a preocupação com a situação do próximo está presente em todos os tipos de sociedade. Até mesmo entre os astecas, povo hodiernamente visto pelo vulgo como violento e insensível, em razão dos sacrifícios humanos praticados em rituais religiosos, o sentimento de solidariedade estava presente. Os soberanos, ao serem investidos no cargo, eram lembrados pelos sacerdotes acerca de seu dever para com as viúvas, órfãos e pobres. ${ }^{6}$

Inegável é a inter-relação entre os princípios religiosos e a solidariedade. É pedra angular do cristianismo o princípio "amarás ao teu próximo como a ti mesmo". 7 O mesmo cristianismo popularizou o pensamento de que "todos são filhos do mesmo Deus" o que não ocorria quando as religiões eram, majoritariamente, politeístas. O atual papa, Bento XVI, dedicou sua primeira carta encíclica ao amor (Carta Encíclica Deus Caritas Est) deixando muito claro o compromisso da Igreja Católica com a caridade.

No islamismo, onde não se pretende uma clara divisão entre Estado e religião, o conceito de redistribuição de bens é bastante perceptível. Existe um tipo de tributo, a zekaa, que funciona como uma verdadeira esmola legal, que a própria lei destina aos necessitados, aos soldados da guerra santa, à libertação de escravos e aos endividados. ${ }^{8}$

No Estado clássico, de orientação liberal, a solidariedade não é posta como um princípio básico de atuação estatal. Embora não chegue a ser desestimulada, a

${ }^{5}$ YAMASHITA, D. Princípio da solidariedade em direito tributário. In: GRECO, M. A.; GODOI, M. S. de. [coord.]. Solidariedade social e tributação. São Paulo: Dialética, 2005. p. 59.

${ }^{6}$ FAEDDA, B. Il principio di ridistribuzione nel diritto tributario e nelle società tradizionali. Diritto \& Diritti - Il Portale Giuridico Italiano. Disponível em: <http://www.diritto.it/materiali/antropologia/faedda.html>. Acesso em: 20 fev. 2006.

7 BIBLIA. Evangelho de Mateus. Disponível em: <http://www.bibliasagrada.web.pt/Mateus3.htm>. Acesso em: 11 jul. 2007.

${ }^{8}$ FAEDDA, op. cit. 
liberdade é tomada como valor mais importante parecendo que a solidariedade é vista como preocupação da sociedade civil e não do Estado. No moderno Estado social, não se tem a mera pretensão de se garantir a liberdade, mas também de estimular a atuação de toda a sociedade em prol da igualdade. Daí a intenção de que a solidariedade deixe de ser apenas algo "desejável” para se tornar atuação obrigatória de toda a sociedade. O estado social não quer ser neutro e propõe-se a corrigir as desigualdades, posicionando-se como protetor do mais fraco. A solidariedade surge como justificadora dessa intenção.

Godói ${ }^{9}$ observa que o conceito de direito de solidariedade torna-se mais delineado pela atuação do trabalhismo, no final do século XIX e no início do século XX, também em razão da crise do estado liberal.

Inegavelmente, o princípio tem bases socialistas, podendo ser considerado um de seus fundamentos. Como afirma Farias ${ }^{10}$, “o discurso do solidarismo jurídico não é somente uma maneira de falar do direito; ele é também um olhar sobre a sociedade como um todo [...]”. O mesmo autor demonstra claramente a interligação entre socialismo e solidariedade, já que "a verdadeira essência do socialismo repousa sobre uma 'filosofia pluralista do direito e da sociedade"”.

De fato, constituem-se projetos muito próximos, quase interligados, "solidariedade, democracia e socialismo" não se podendo entender uma sociedade como solidária que não se constitua sob o regime democrático ou onde paire grandes desigualdades. A solidariedade não prescinde do desejo de liberdade (preocupação individualista, também acatada pela Constituição), mas, indubitavelmente, a busca da igualdade é seu maior escopo.

Não pode ser visto como solidário o cidadão que somente age em busca de seus próprios interesses, sendo certo que a opção pela solidariedade implica também na renúncia de parcela de certas vantagens pessoais. É, portanto, um conceito

${ }^{9}$ GODOI, M. S. de. Tributo e solidariedade social. In: GRECO, M. A.; GODOI, M. S. de. [coord.]. Solidariedade social e tributação. São Paulo: Dialética, 2005. p. 143.

${ }^{10}$ FARIAS, J. F. de C. A origem do direito de solidariedade. Rio de Janeiro: Renovar, 1998, p. 275. 
socialista, que vê o Estado não apenas como defensor da liberdade, mas também como responsável maior pelo bem comum.

Não era de se surpreender que esse sentimento já presente desde a origem humana nas regras de convivência viesse a ser, de alguma forma, positivado:

Podemos dizer que, descontadas algumas manifestações constantes, primeiro, da declaração de direitos da (rejeitada) Constituição girondina e depois, da declaração de direitos da Constituição jacobina, em que as exigências da solidariedade se apresentavam já claramente afirmadas, a idéia da solidariedade apenas vai ser (re) descoberta no dobrar do século XIX para o século XX, através duma espécie de frente comum formada sobretudo por teóricos franceses, em que encontramos economistas como Charles Gide, sociólogos como Émile Durkeim e juristas como Léon Duguit, Maurice Hauriou e Georges Gurvitch. ${ }^{11}$

A Declaração Universal dos Direitos Humanos, de 1948, apresenta evidentes traços solidarísticos, embora não contenha literalmente a expressão "solidariedade"12. Porém, como lembra Godói ${ }^{13}$, o preâmbulo menciona que todas as pessoas são "membros da família humana", e no art. $1^{\circ}$ dispõe que todos "devem agir uns para com os outros em espírito de fraternidade".

Dessas energias existentes em maior ou menor grau na sociedade, e dos princípios e forças já mencionados, a sociedade brasileira fez insculpir o princípio em sua Constituição. De forma expressa, ele aparece na Constituição como um objetivo fundamental da República Federativa do Brasil: "Art. 3․ Constituem objetivos fundamentais da República Federativa do Brasil: I - construir uma sociedade livre, justa e solidária; [...]."14

Trata-se, concomitantemente, de um objetivo e de um princípio constitucional:

${ }^{11}$ NABAIS, op. cit., p. 110-111.

12 ORGANIZAÇÃO DAS NAÇÕES UNIDAS. Declaração dos direitos humanos. Disponível em: <http://www.onu-brasil.org.br/documentos_direitoshumanos.php>. Acesso em: 10 jul. 2007.

${ }^{13}$ GODOI, op. cit., p. 143.

14 BRASIL. Constituição Federal de 1988. Disponível em: < http://www.planalto.gov.br/ccivil_03/Constituicao/Constituiçao_Compilado.htm>. Acesso em: 04 jul. 2007. 
Assim, é possível afirmar que quando a Constituição estabelece como um dos objetivos fundamentais da República brasileira "construir uma sociedade justa, livre e solidária", ela não está apenas enunciando uma diretriz política desvestida de qualquer eficácia normativa. Pelo contrário, ela expressa um princípio jurídico, que, apesar de sua abertura e indeterminação semântica, é dotado de algum grau de eficácia imediata e que pode atuar, no mínimo, como vetor interpretativo da ordem jurídica como um todo. ${ }^{15}$

Em verdade, o princípio encontra-se tacitamente presente em toda a Constituição, servindo não apenas como mecanismo de interpretação ou reafirmação de outros princípios, mas também como fundamento da própria ordem constitucional.

Vários dispositivos constitucionais estão intimamente relacionados com o princípio da solidariedade, cabendo exemplificar com os artigos 40, 194, 195, 196, $203,205,227$ e $230 .^{16}$

Nas Constituições anteriores, o princípio não poderia ser tomado como fundamental, embora estivesse presente em algumas matérias, como orientador de temas específicos.

A Constituição de $1967^{17}$ mencionava ser princípio da ordem econômica a "harmonia e solidariedade entre as categorias sociais de produção" (art. 160, inc. IV).

${ }^{15}$ SARMENTO, D. Direitos fundamentais e relações privadas. 2. ed. Rio de Janeiro: Lumen Juris, 2006, p. 295.

${ }^{16}$ Art. 40. "Aos servidores titulares de cargos efetivos da União, dos Estados, do Distrito Federal e dos Municípios, incluídas suas autarquias e fundações, é assegurado regime de previdência de caráter contributivo e solidário, [...]".

Art. 194. "A seguridade social compreende um conjunto integrado de ações de iniciativa dos Poderes Públicos e da sociedade, [...]".

Art. 195. "A seguridade social será financiada por toda a sociedade, $[\ldots] "$.

Art. 196. "A saúde é direito de todos e dever do Estado, [...]".

Art. 203. "A assistência social será prestada a quem dela necessitar, independentemente de contribuição à seguridade social, [...]".

Art. 205. "A educação, direito de todos e dever do Estado e da família, será promovida e incentivada com a colaboração da sociedade, [...]".

Art. 227. "É dever da família, da sociedade e do Estado assegurar à criança e ao adolescente, $[\ldots] "$.

Art. 230. "A família, a sociedade e o Estado têm o dever de amparar as pessoas idosas, [...]".

17 BRASIL. Constituição Federal de 1967. Disponível em: < http://www.planalto.gov.br/ccivil_03/Constituicao/Emendas/Emc_anterior1988/emc01-69.htm>. 
Citava-se a solidariedade como um princípio da área educacional (art. 176) o mesmo ocorrendo com as Constituições de 1946 (art. 176) ${ }^{18}$ e de 1934 (art. 149) ${ }^{19}$ que também lembravam o princípio da solidariedade humana, mas limitado ao capítulo educacional. A Constituição de $1937^{20}$ apresentava, também na área educacional, “o dever de solidariedade dos menos para com os mais necessitados", expressão que constou do art. 130.

Recuando-se no tempo, ver-se-á que as Constituições de $1824^{21}$ e $1891^{22}$ sequer continham a palavra "solidariedade".

Obviamente, não é pelo fato de inexistir a palavra "solidariedade" no texto constitucional que se poderia disso deduzir que o Estado não tivesse nenhuma intenção solidarística. Desde a Constituição de 1934 as preocupações sociais estavam claramente presentes, em especial pelo advento do Estado social.

Entretanto, considerando-se o tema como princípio e objetivo central do ordenamento, constata-se que o assunto é relativamente recente, dizendo respeito à Constituição de 1988 que, ao alçar o princípio à categoria de fundamental, inova em relação às Constituições antecessoras. ${ }^{23}$

Comparando-se as Constituições mais recentes (1967 e 1988) Greco ${ }^{24}$ observa

Acesso em: 04 jul. 2007.

18 BRASIL. Constituição Federal de 1946. Disponível em: < http://www.planalto.gov.br/ccivil_03/Constituicao/Constitui\%E7ao46.htm>. Acesso em: 04 jul. 2007.

19 BRASIL. Constituição Federal de 1934. Disponível em: < http://www.planalto.gov.br/ccivil_03/Constituicao/Constitui\%E7ao34.htm>. Acesso em: 04 jul. 2007.

20 BRASIL. Constituição Federal de 1937. Disponível em: < http://www.planalto.gov.br/ccivil_03/Constituicao/Constitui\%E7ao37.htm>. Acesso em: 04 jul. 2007.

21 BRASIL. Constituição Federal de 1824. Disponível em: < http://www.planalto.gov.br/ccivil_03/Constituicao/Constitui\%E7ao24.htm>. Acesso em: 04 jul. 2007.

22 BRASIL. Constituição Federal de 1891. Disponível em: < http://www.planalto.gov.br/ccivil_03/Constituicao/Constitui\%E7ao91.htm>. Acesso em: 04 jul. 2007.

${ }^{23}$ Segundo GODÓI (op. cit., p. 142) a atual Constituição brasileira, assim como a italiana, inspirou-se claramente na Constituição Portuguesa de 1976 que declara, em seu art. $1^{\circ}$, o dever da República construir uma "sociedade livre, justa e solidária".

${ }^{24}$ GRECO, M. A. Solidariedade social e tributação. In: GRECO, M. A.; GODOI, M. S. de. [coord.]. Solidariedade social e tributação. São Paulo: Dialética, 2005. p. 170. 
interessante mudança de visão na relação entre Estado e cidadão. Ao se analisar a Constituição de 1967 percebe-se que os primeiros capítulos dedicam-se à formação do Estado, deixando para um segundo momento a regulação da sociedade. Ao contrário, a Constituição de 1988 primeiro dispõe sobre os direitos fundamentais para depois adentrar na regulamentação do Estado. Demonstra-se que a atual Constituição vê a sociedade como formadora e conformadora o Estado e não o contrário.

Numa sociedade tão desigual como a brasileira, estudar o assunto passa a ser de suma importância. Como afirma Sacchetto: "[...] hoje existe o risco de perder o conceito de responsabilidade pública, que os cidadãos deixem de ter consciência que uma parte de suas vidas deve ser gerida em comum com os outros: este é o significado real da solidariedade, como ensina a etimologia do termo (do latim "in solido")". ${ }^{25}$

\section{SOLIDARIEDADE E AS DIMENSÕES DE DIREITOS}

Bonavides $^{26}$ menciona que os direitos de quarta dimensão ${ }^{27}$ seriam aqueles que atinem à democracia, à informação e ao pluralismo. Nessa clássica concepção das "dimensões de direitos", podem-se localizar os direitos de solidariedade como posicionados na mais recente "onda" de direitos, ou seja, a quarta dimensão, havendo óbvia interligação, por exemplo, entre solidariedade e meio ambiente (pode-se afirmar que há uma solidariedade entre gerações) ou solidariedade e democracia. Muito embora a indicação de quais seriam, exatamente, os afirmados direitos de "quarta geração" seja ainda discutível, pairando discussões atinentes à própria existência desses direitos ${ }^{28}$, a verdade é que a idéia de solidariedade está em plena consonância

${ }^{25}$ SACCHETTO, op. cit., p. 9-52.

${ }^{26}$ BONAVIDES, P. Curso de direito constitucional. 19. ed. São Paulo: Malheiros, 2006, p. 569.

${ }^{27}$ (Ibidem, p. 571), dentre outros, defende a substituição do usual termo "geração" por "dimensão", sugestão acatada neste artigo.

${ }^{28}$ BREGA FILHO, V. Direitos fundamentais na Constituição de 1988: conteúdo jurídico das 
com as modernas preocupações do direito, em razão da chamada quarta geração de direitos fundamentais, constituída justamente pelos designados "direitos ecológicos" ou "direitos de solidariedade". 29

Canotilho observa:

\begin{abstract}
A partir da década de 60, começou a desenhar-se uma nova categoria de direitos humanos vulgarmente chamados direitos da terceira geração. Nesta perspectiva, os direitos do homem reconduzir-se-iam a três categorias fundamentais: os direitos de liberdade, os direitos de prestação (igualdade) e os direitos de solidariedade. Estes últimos direitos, nos quais se incluem o direito ao desenvolvimento, o direito ao patrimônio comum da humanidade pressupõem o dever de colaboração de todos os estados e não apenas o actuar activo de cada um e transportam uma dimensão colectiva justificadora de um outro nome dos direitos em causa: direitos dos povos. Por vezes, estes direitos são chamados direitos de quarta geração. $^{30}$
\end{abstract}

Entretanto, não seria equivocado situar a solidariedade entre os direitos de terceira geração, inclusive pela proximidade entre os termos "solidariedade" e "fraternidade", terceiro item do lema preconizado pela Revolução Francesa. ${ }^{31}$ Aceita a proximidade dos termos, o princípio da solidariedade poderia ser situado como direito de terceira dimensão: “A teoria, com Vasak e outros, já identificou cinco direitos da fraternidade, ou seja, da terceira geração: o direito ao desenvolvimento, o direito à paz, o direito ao meio ambiente, o direito de propriedade sobre o patrimônio comum da humanidade e o direito de comunicação.",32

De fato, muitos autores titulam os chamados direitos de terceira geração como “direitos de solidariedade". Segundo informa Robert Pelloux ${ }^{33}$, na abertura dos cursos

expressões. São Paulo: Juarez de Oliveira, 2002, p. 24-25.

${ }^{29}$ NABAIS, op. cit., p. 111.

${ }^{30}$ CANOTILHO, J. J. G. Direito constitucional e teoria da Constituição. 6. ed. Coimbra: Almedina, 2002, p. 386.

${ }^{31}$ Consigne-se, porém, que o termo "fraternitè" da Revolução Francesa tinha inclinação para a idéia de filantropia ou caridade, enquanto que solidariedade social, agora um conceito jurídico, tem características mais objetivas. (GODÓI, op. cit., p. 143)

32 BONAVIDES, op. cit., p. 569.

33 Apud FERREIRA FILHO, M. G. Direitos humanos fundamentais. 8. ed. rev. ampl. São Paulo: Saraiva, 2006, p. 57. 
do Instituto Internacional dos Direitos do Homem, em 1979, foi Karel Vasak quem primeiro apontou a existência dessa terceira dimensão de direitos, chamando-os exatamente de "direitos de solidariedade".

Intuitivamente percebe-se que, independentemente da discussão acerca da existência dos direitos de quarta dimensão, a solidariedade tem íntima relação com os chamados direitos de terceira dimensão recém-mencionados.

É importante não se confundir, porém, a nomenclatura eventualmente aplicada aos direitos de terceira (ou mesmo quarta) dimensão - direitos de solidariedade - com o princípio da solidariedade, objeto do presente estudo. No primeiro caso, tem-se uma designação genérica de direitos; no segundo, um princípio constitucional específico.

Conclui-se, pois, que o princípio da solidariedade tem íntima relação com os chamados direitos de terceira dimensão o que não significa dizer que não represente, também, direito de quarta dimensão, já que uma nova onda de direitos não suplanta a anterior.

\section{SOLIDARIEDADE E DIREITOS FUNDAMENTAIS}

A solidariedade é, a um só tempo, valor e princípio. ${ }^{34}$ Porém, ao ingressar na esfera jurídica, o valor moral sofre, obviamente, algumas adequações: não é mais um mero sentimento íntimo ou uma regra moral. Por isso, nesse estágio, torna-se irrelevante se o indivíduo, a quem é também destinada a norma constitucional, está de acordo ou não com ela:

É óbvio que o Direito não tem como penetrar no psiquismo das pessoas para impor-lhes as virtudes da generosidade e do altruísmo. Seria terrível, aliás, se o Direito pudesse ditar sentimentos. Entretanto, se ele não pode obrigar ninguém a pensar ou a sentir de determinada

${ }^{34}$ TORRES, R. L. Existe um princípio estrutural da solidariedade? In: GRECO, M. A.; GODOI, M. S. de. [coord.]. Solidariedade social e tributação. São Paulo: Dialética, 2005. p. 198. 
forma, ele pode, sim, condicionar o comportamento externo dos agentes, vinculando-os a obrigações jurídicas. $^{35}$

Lendo-se os primeiros artigos da Constituição, vê-se que ela "impôs, com certa prevalência axiológica abstrata, o dever de perseguir os ideais de dignidade e de solidariedade." 36

Por isso, toda a Constituição está ungida pela idéia da solidariedade. Já no preâmbulo, evidencia-se o desejo dos Constituintes de construir uma sociedade onde reine "a igualdade e justiça como valores supremos de uma sociedade fraterna.",37

Sob a ótica da solidariedade, o Estado Democrático de Direito, implantado pelo art. $1^{\mathrm{o}}$ da Constituição, consiste na persecução de:

i) justiça social (arts. $3^{\circ}$, I, 170, caput, e 193 da CF/88) que busca redistribuição de renda e igualdade de chance a todos, ou seja, a capacidade existencial, econômica e cultural para viver e trabalhar, num nível razoável; e ii) segurança social, ou seja, a) bem-estar social (arts. 186, VI, e 193 da CF/88), consubstanciado especialmente na proteção existencial, garantida pela prestação de serviços públicos básicos (água, luz, transporte, educação, saúde etc.) e nos seguros sociais (seguro-desemprego, seguro por invalidez etc.) e b) assistência social (auxílio mínimo existencial e auxílios em catástrofes naturais, a fim de garantir um mínimo de dignidade humana ao cidadão). ${ }^{38}$

Vê-se que cidadania e solidariedade são conceitos irmãos. Nabais ${ }^{39}$ fala em cidadania solidária. Comenta que, num primeiro estágio, a cidadania era entendida como uma situação de passividade, traduzida na "liberdade comum" a ser usufruída por todos os cidadãos, destinada à preservação da vida, liberdade e propriedade. Num segundo instante, a idéia de cidadania passa a ter um conteúdo ativo, passando a designar mais propriamente a atuação no indivíduo na condução do Estado. Cidadania

\footnotetext{
${ }^{35}$ SARMENTO, op. cit., p. 297.
}

${ }^{36}$ ÁVILA, H. Limites à tributação com base na solidariedade social. In: GRECO, M. A.; GODOI, M. S. de. [coord.]. Solidariedade social e tributação. São Paulo: Dialética, 2005. p. 68.

${ }^{37}$ BRASIL. Constituição Federal de 1988, op. cit.

${ }^{38}$ YAMASHITA, op. cit., p. 59.

${ }^{39}$ NABAIS, op. cit., p. 124-125. 
é tema diretamente ligado à idéia do voto e da ampla participação política. Por fim, chega-se a um terceiro estágio, no qual se incorpora a idéia de cidadania solidária em que o cidadão assume a condição de protagonista na vida pública.

O cidadão não mais depende do Estado para atuar; é, também, seu direito e dever laborar pela implementação das reformas sociais desejadas pela Constituição.

Utilizando-se do mesmo raciocínio, especificamente quanto ao princípio da solidariedade, Nabais $^{40}$ classifica-a quanto aos seus efeitos em vertical e horizontal. A primeira visão - solidariedade vertical - seria aquela mais comumente identificada com os deveres do Estado. Constituindo-se um Estado social, os órgãos públicos estão obrigados a buscar a minimização das desigualdades, corrigindo os desníveis sociais, implantando e efetivando os direitos em benefício de todos os membros da sociedade: "Podemos dizer que foi este tipo de solidariedade a que foi convocada para a resolução da chamada questão social, quando a pobreza deixou de ser um problema individual e se converteu num problema social a exigir intervenção política."

Por outro lado, a solidariedade pode também ser vista em seu sentido horizontal, agora não tomada apenas como um dever do Estado, mas também como obrigação de toda a sociedade civil. Determina a solidariedade que a efetivação dos direitos fundamentais seja vista como obrigação não apenas do Estado, mas da própria sociedade. ${ }^{42}$ Cada cidadão é, também, vinculado à idéia de solidariedade.

Essa segunda noção - solidariedade horizontal - como vinculadora da própria sociedade vem adquirindo especial importância pela verificação das limitações do Estado em garantir os direitos constitucionais. Segundo Nabais, ${ }^{43}$ essa manifestação da sociedade civil pode ser visualizada em duas constatações:

1) uma, concretizada na atuação espontânea dos indivíduos e grupos sociais, que nunca

\footnotetext{
${ }^{40}$ Ibidem, loc. cit.

${ }^{41}$ Ibidem, p. 115.

${ }^{42}$ Ibidem, p. 114-115.

${ }^{43}$ Ibidem, p. 116.
} 
deixaram de atuar socialmente mesmo quando o Estado social, apoiado no seu crescimento constante, chegou a julgar-se capaz de realizar todos os anseios dos seus cidadãos e substituir por inteiro a sociedade civil; 2) outra, expressa na solicitação e empenhamento do próprio Estado que, reconhecendo a sua incapacidade, mesmo quando atingiu a forma superlativa do Estado social, isto é, o Estado de bem-estar, se voltou para a sociedade civil.

A noção de "dever de solidariedade" é, portanto, o estágio mais avançado da cidadania.

O princípio da solidariedade "explica" a existência de diversos direitos fundamentais abrangidos pela Constituição. Pode ser encarado como a contraprestação devida pela existência dos direitos fundamentais: se tenho direitos, tenho, em contrapartida, o dever de prestar solidariedade àqueles que se encontram em posição mais frágil que a minha.

À parte dos direitos fundamentais, é notável a importância do princípio da solidariedade no campo do direito tributário. Indiscutivelmente, o sistema tributário brasileiro tem bases calcadas no princípio da solidariedade, visto que aquele que paga tributos não tem uma compensação direta e imediata por aquilo que pagou (salvo no caso das taxas e contribuições de melhoria). Não há, por assim dizer, uma relação sinalagmática. Talvez por essa razão a maioria dos estudos levados a cabo sobre o princípio da solidariedade, no Brasil, foram realizados por tributaristas, o que denota a preocupação em se buscar uma justificativa ética para o dever de pagar tributos. ${ }^{44}$

Sobre os direitos fundamentais - objeto do presente estudo - rápida leitura sobre alguns dispositivos constitucionais comprova a direta interferência do princípio da solidariedade sobre o pensamento constitucional.

O princípio da igualdade (caput do art. $5^{\circ}$ da Constituição Federal), por exemplo, encontra-se interligado à idéia de solidariedade, pois se constituímos um todo, somos, ao menos em direitos, iguais, não se podendo vislumbrar sociedade efetivamente solidária sem que haja igualdade.

\footnotetext{
${ }^{44}$ Entretanto, nem sempre foi assim, constatando-se que, em regra, a história da tributação demonstra que a tributação serviu muito mais como forma de acumulação de riquezas em favor dos ricos, em detrimento dos pobres. (NOGUEIRA, A. A reconstrução dos direitos humanos da
} 
A liberdade para criação de associações e cooperativas (art. $5^{\circ}$, inc. XVIII) também encontra justificativa na solidariedade existente entre os membros da sociedade, ainda mais forte quando os indivíduos encontram laços de interesse que justificam uma mais forte unificação, sendo plenamente justificável, dessa forma, a possibilidade de representação judicial desses grupamentos de indivíduos pelas entidades criadas por eles (art. $5^{\circ}$, inc. XXI).

Ao lado do princípio de cunho individualista, que garante o direito de propriedade (art. $5^{\circ}$, inc. XXII) a Constituição dispõe, também, que a propriedade deve atender sua função social (art. $5^{\circ}$, inc. XXIII). Trata-se de óbvio norte socialista e solidarista, pois o indivíduo, que tem direito à propriedade, pode destiná-la para o seu benefício pessoal, mas deve também direcioná-la ao interesse dos demais membros da sociedade. Disso decorrem outros mecanismos legais e constitucionais como a possibilidade de desapropriação ou direito de uso da propriedade pelo Poder Público em determinadas circunstâncias (art. $5^{\circ}$, incs. XXIV e XXV).

Como não poderia deixar de ser, sendo objetivo constitucional a construção de uma sociedade solidária, a própria Constituição repudia de maneira especial atitudes anti-solidárias como a prática do racismo, tangendo-o como crime inafiançável (art. $5^{\circ}$, inc. XLII). No mesmo tom, o Poder Constituinte originário repudiou outras práticas tidas como graves atentados à solidariedade social, como o tráfico ilícito de entorpecentes, o terrorismo e os definidos como crimes hediondos (art. $5^{\circ}$, inc. XLIII).

A solidariedade não deixa de socorrer até mesmo aqueles que foram condenados criminalmente, sendo que a Constituição prevê uma série de limites às penas legais, assegurando ao preso direitos intocáveis pelo Estado e, ao cidadão comum, instrumentos (garantias) que lhe permitam assegurar-se contra os desmandos dos órgãos estatais (art. $5^{\circ}$, incs. XLV a LXXII).

Principal executor dos atos de solidariedade, o Estado "prestará assistência jurídica integral e gratuita aos que comprovem insuficiência de recursos" (art. $5^{\circ}$, inc. LXXIV). Trata-se de preocupação de acesso à justiça, de forma que todos, 
indistintamente, possam recorrer ao Judiciário visando assegurar seus direitos.

Também o princípio da solidariedade determina que certos documentos essenciais sejam gratuitos para os reconhecidamente pobres (art. $5^{\circ}$, inc. LXXVI).

Cabe destacar, ainda, que o princípio em questão é inspirador até mesmo das relações internacionais, constando do art. $4^{\circ}$ da Constituição que a República Federativa do Brasil que tem, como princípio de suas relações internacionais, o de "cooperação entre os povos para o progresso da humanidade". ${ }^{45}$ Trata-se de clara aplicação do princípio da solidariedade ao âmbito internacional.

De forma superficial (já que não se pretende estudar os direitos fundamentais em espécie, mas apenas a relação destes com os ideais solidaristas), foram lembrados alguns dispositivos constitucionais, nos quais, a inspiração do princípio da solidariedade foi bastante clara, mas há que se reafirmar que o mencionado princípio, em realidade, é notável em muitos outros pontos da Constituição.

Além de orientador interpretativo, aplicativo e legislativo, o princípio da solidariedade também pode justificar a aplicação do princípio da proibição do retrocesso $^{46}$ assim definido por Sarlet:

Em linhas gerais, o que se percebe é que a noção de proibição de retrocesso tem sido por muitos reconduzida à noção que José Afonso da Silva apresenta como sendo de um direito subjetivo negativo, no sentido de que é possível impugnar judicialmente toda e qualquer medida que se encontre em conflito com o teor da Constituição (inclusive com os objetivos estabelecidos nas normas de cunho programático), bem como rechaçar medidas legislativas que venham, pura e simplesmente, subtrair supervenientemente a uma norma constitucional o grau de concretização anterior que lhe foi outorgado pelo legislador. ${ }^{47}$

Na hipótese, portanto, de tentativa de supressão ou redução dos direitos fundamentais, caberia a invocação do princípio da vedação do retrocesso que, por sua

${ }^{45}$ BRASIL. Constituição Federal de 1988, op. cit.

${ }^{46}$ SARMENTO, op. cit., p. 298.

${ }^{47}$ SARLET, I. W. Direitos fundamentais sociais e proibição de retrocesso: algumas notas sobre o desafio da sobrevivência dos direitos sociais num contexto de crise. Revista do Instituto de Hermenêutica Jurídica, Porto Alegre, p. 147, 2004. 
vez, encontra-se justificado ou ao menos fortalecido pelo princípio da solidariedade.

Este último exemplo demonstra quão útil é a utilização do princípio quando se tem em mente a efetivação dos direitos fundamentais. Farias ${ }^{48}$ afirma que "o direito de solidariedade é situado num espaço complexo que repudia o formalismo jurídico e toda visão monista do direito e do poder". O princípio é, ao mesmo tempo, unificador da sociedade, afastando-se da concepção de "luta de classes" e vinculando-se a idéia de cooperação e convívio: "A solidariedade, como um dos fundamentos da democracia, supõe combinar sempre três dimensões: o consenso, que é a referência às orientações culturais comuns; o conflito, que opõe os adversários; o compromisso, que combina esse conflito com o respeito de um quadro social - em particular jurídico que o limita." 49

Constata-se que o princípio da solidariedade tem importância grandiosa quando a preocupação e a intenção do jurista forem a efetivação dos direitos fundamentais.

\section{CONCLUSÃO}

Diante da noção intuitiva (duvidosa) de que a todo direito corresponde um dever, poder-se-ia dizer que o correspondente aos direitos fundamentais é o dever de solidariedade. De fato, este último há de ser visto mais como dever do que propriamente direito, sobressaindo-se como força antagônica ao individualismo de nossos dias.

De início mero valor moral, o princípio da solidariedade tornou-se, por via da Constituição de 1988, direito positivo, passando a não representar apenas sentimento

\footnotetext{
${ }^{48}$ FARIAS, op. cit., p. 280.

${ }^{49}$ Ibidem, p. 284.
} 
pessoal ou aspiração de grupos. Hoje é dever de toda a sociedade prestar auxílio aos fracos e desamparados, ainda que esse desejo possa inexistir no íntimo de alguns ou muitos cidadãos.

De certa forma, o princípio da solidariedade serve para explicar "por que razão" deve ser materializado os direitos fundamentais, constituindo, além de princípio, um sentimento fundador de todo o arcabouço legal. Diz, portanto, não apenas "o que deve ser implementado", mas também responde "por que deve ser implementado". Afirmar que se deseja a efetivação dos direitos fundamentais apenas porque a Constituição assim determina equivale a dizer que não se mata porque a lei não o permite. Uma sociedade estruturada apenas na lei não pode ser bem sucedida; há que haver um sentimento prévio à própria ordem jurídica que a respalde. Quando o art. $3^{0}$ da Constituição afirma que um dos objetivos da República é a construção de uma sociedade livre, justa e solidária, assim fala em respeito ao desejo da ampla maioria dos cidadãos que nutre esse sonho.

No campo tributário, a atuação do princípio da solidariedade torna-se muito clara. Obviamente, ninguém tem prazer em pagar tributos; paga-se, dentre outras razões, por dever de solidariedade (em sentido jurídico). O sentimento íntimo daquele que paga (por desejo de colaborar com o Estado, por temor da lei etc.) é totalmente irrelevante. Entretanto, compreende-se que o tributo é o preço que se paga pela Democracia.

Tal como ocorre em outras paragens do direito, o princípio da solidariedade deve ser aproveitado com parcimônia e sabedoria: até mesmo ele pode ser mal utilizado e, se o for, pode representar riscos ao próprio Estado de direito. Em nenhuma hipótese deve servir para justificar atentados contra direitos humanos, por exemplo, o que poderia ocorrer numa interpretação excessivamente social do direito. De fato, teme-se que o princípio da solidariedade seja tomado em proporções excessivas, servindo para justificar quaisquer atos em nome do "bem comum", o que permitiria que direitos individuais fundamentais fossem postados abaixo dos interesses da sociedade. 
Esta concepção excessiva do princípio da solidariedade, vazada na idéia de que o indivíduo deve servir ilimitadamente à sociedade, pode conduzir ao autoritarismo, como já ocorreu com os regimes nazista e fascista que apresentavam exatamente esse pensamento. Por essa razão, o princípio da solidariedade deve ser adotado e efetivado, mas em plena harmonia com os demais princípios constitucionais. Direitos humanos não podem ser postos de lado sob o argumento da solidariedade.

À parte dos mencionados riscos (que, diga-se, não se restringem apenas a este princípio), procurou-se demonstrar que o princípio da solidariedade tem juridicidade, devendo ser visto como basilar da ordem constitucional (no sentido criativo e interpretativo), além de servir como justificador de direitos fundamentais.

Sua grande virtude é harmonizar-se com as diversas correntes ideológicas: não prescinde da liberdade, tem íntima ligação com a noção de cidadania, almeja a diminuição das desigualdades e baseia-se na idéia de cooperação.

Tem, ainda, o mérito de ser instrumento de enriquecimento e humanização do direito, trazendo para o seio do estudo jurídico valores indiscutivelmente nobres e essenciais para a vida em sociedade.

\section{REFERÊNCIAS}

ÁVILA, H. Limites à tributação com base na solidariedade social. In: GRECO, M. A.; GODOI, M. S. de. [coord.]. Solidariedade social e tributação. São Paulo: Dialética, 2005. p. 68-88.

BIBLIA. Evangelho de Mateus. Disponível em: <http://www.bibliasagrada.web.pt/Mateus3.htm>. Acesso em: 11 jul. 2007.

BOBBIO, N. A era dos direitos. Trad. Carlos Coutinho. Rio de Janeiro: Elsevier, 2004.

BONAVIDES, P. Curso de direito constitucional. 19. ed. São Paulo: Malheiros, 2006. 
BRASIL. Constituição Federal de 1824. Disponível em: < http://www.planalto.gov.br/ccivil_03/Constituicao/Constitui\%E7ao24.htm>. Acesso em: 04 jul. 2007.

Constituição Federal de 1891. Disponível em: < http://www.planalto.gov.br/ccivil_03/Constituicao/Constitui\%E7ao91.htm>. Acesso em: 04 jul. 2007.

Constituição Federal de 1934. Disponível em: < http://www.planalto.gov.br/ccivil_03/Constituicao/Constitui\%E7ao34.htm>. Acesso em: 04 jul. 2007.

Constituição Federal de 1937. Disponível em: < http://www.planalto.gov.br/ccivil_03/Constituicao/Constitui\%E7ao37.htm>. Acesso em: 04 jul. 2007.

_. Constituição Federal de 1946. Disponível em: < http://www.planalto.gov.br/ccivil_03/Constituicao/Constitui\%E7ao46.htm>. Acesso em: 04 jul. 2007.

Constituição Federal de 1967. Disponível em: < http://www.planalto.gov.br/ccivil_03/Constituicao/Emendas/Emc_anterior1988/emc01 -69.htm>. Acesso em: 04 jul. 2007.

Constituição Federal de 1988. Disponível em: < http://www.planalto.gov.br/ccivil_03/Constituicao/Constituiçao_Compilado.htm>. Acesso em: 04 jul. 2007.

BREGA FILHO, V. Direitos fundamentais na Constituição de 1988: conteúdo jurídico das expressões. São Paulo: Juarez de Oliveira, 2002.

CANOTILHO, J. J. G. Direito constitucional e teoria da Constituição. 6. ed. Coimbra: Almedina, 2002.

CASSONE, V. Direito tributário. 17. ed. São Paulo: Atlas, 2006.

FACHIN, Z. Teoria geral do direito constitucional. 2. ed. rev. atual. Londrina: UEL, 2006.

FAEDDA, B. Il principio di ridistribuzione nel diritto tributario e nelle società tradizionali. Diritto \& Diritti - Il Portale Giuridico Italiano. Disponível em: <http://www.diritto.it/materiali/antropologia/faedda.html>. Acesso em: 20 fev. 2006.

FARIAS, J. F. de C. A origem do direito de solidariedade. Rio de Janeiro: Renovar, 1998.

FERREIRA FILHO, M. G. Direitos humanos fundamentais. 8. ed. rev. ampl. São Paulo: Saraiva, 2006. 
GODOI, M. S. de. Tributo e solidariedade social. In: GRECO, M. A.; GODOI, M. S. de. [coord.]. Solidariedade social e tributação. São Paulo: Dialética, 2005. p. 141-167.

GRECO, M. A. Solidariedade social e tributação. In: GRECO, M. A.; GODOI, M. S. de. [coord.]. Solidariedade social e tributação. São Paulo: Dialética, 2005. p. 168-189.

MACHADO, H. de B. Curso de direito tributário. 27. ed. rev. atual. ampl. São Paulo: Malheiros, 2006.

MARINONI, L. G. Teoria geral do processo. São Paulo: RT, 2006. v. 1.

MEZZAROBA, O.; MONTEIRO, C. S. Manual de metodologia da pesquisa no direito. 2. ed. São Paulo: Saraiva, 2005.

MORAIS, J. L. B. de. As crises do Estado e da Constituição e a transformação espacial dos direitos humanos. Porto Alegre: Livraria do Advogado, 2002.

NABAIS, J. C. Solidariedade social, cidadania e direito fiscal. In: GRECO, M. A.; GODOI, M. S. de. [coord.]. Solidariedade social e tributação. São Paulo: Dialética, 2005. p. 110-140.

NOGUEIRA, A. A reconstrução dos direitos humanos da tributação. Rio de Janeiro: Renovar, 1997.

ORGANIZAÇÃO DAS NAÇÕES UNIDAS. Declaração dos direitos humanos. Disponível em: <http://www.onu-brasil.org.br/documentos_direitoshumanos.php>. Acesso em: 10 jul. 2007.

RIOS, D. R. Dicionário global da língua portuguesa. 4. ed. São Paulo: DCL, 2004.

SACCHETTO, C. Solidariedade social e tributação. In: GRECO, M. A.; GODOI, M. S. de. [coord.]. Solidariedade social e tributação. São Paulo: Dialética, 2005. p. 9-52.

SARLET, I. W. Direitos fundamentais sociais e proibição de retrocesso: algumas notas sobre o desafio da sobrevivência dos direitos sociais num contexto de crise. Revista do Instituto de Hermenêutica Jurídica, Porto Alegre, 2004.

SARMENTO, D. Direitos fundamentais e relações privadas. 2. ed. Rio de Janeiro: Lumen Juris, 2006.

TORRES, R. L. Existe um princípio estrutural da solidariedade? In: GRECO, M. A.; GODOI, M. S. de. [coord.]. Solidariedade social e tributação. São Paulo: Dialética, 2005. p. 198-207.

YAMASHITA, D. Princípio da solidariedade em direito tributário. In: GRECO, M. A.; GODOI, M. S. de. [coord.]. Solidariedade social e tributação. São Paulo: Dialética, 2005. p. 53-67. 


\begin{abstract}
SUMMARY: It talks about the constitutional principle of the solidarity, inter-related it to the fundamental rights. It weaves historical abbreviation on the origins of the principle of the solidarity, fixing them in the Christianity and in the socialist ideals. It fixes the bases of written right that make mention to the principle of the solidarity, as the current Brazilian Constitution and the Universal Declaration of the Human Rights. It analyzes the presence of the principle of the solidarity in the already revoked Brazilian constitutions. It tries to place the principle of the solidarity in the classification of the rights in dimensions (or generations) concluding that the same can be classified as of third or fourth dimension, in agreement with the adopted criteria. It proves the existent relationship between the principle of the solidarity and the fundamental rights, mentioning some rights foreseen in the Constitution, intimately linked to the principle in subject. It demonstrates the influence of the principle of the solidarity in the tax right. It points out the importance of the study of the principle for the constitutional right, since it contributes to the humanization of the right. It finishes off defending the importance of the principle as a contribution for making effective the fundamental rights and as a justification of the own existence of those rights
\end{abstract}

KEY-WORDS: Solidarity; Fundamental Rights; Dimensions of Rights; Constitutional Principles. 